\title{
Measurements of dynamic surface strains induced by blasting near a highwall of a coal mine - a preliminary assessment
}

\author{
K.N. Henley Orica Australia Pty Ltd, Australia
}

A.T. Spathis Orica Australia Pty Ltd, Australia

\begin{abstract}
Five production blasts at a coal mine were monitored at the top of the highwall using multiple vibration monitors from which the two dimensional transient surface strains were inferred using a novel analysis method. The rock type at the top of the highwall was semi-consolidated sediments typical of natural surface cover in central Queensland coal mines. The monitors were located between 81 and 280 metres from the production blasts, and approximately $10 \mathrm{~m}$ from the highwall crest. Vibration levels recorded were between 50 and $226 \mathrm{~mm} / \mathrm{s}$, while maximum tensile principal strains were between 123 and 542 microstrain. No obvious surface cracks were noted at the monitoring location.
\end{abstract}

\section{Introduction}

Measurement of blast generated vibration is a common technique used to assess the impact of blasting on infrastructure surrounding a mine or quarry. Although vibration does not measure directly the nucleation and extension of cracks that relate to damage, many years of experience link vibration and frequency to damage to infrastructure and this has led to the development of vibration criteria useful for estimating damage. Vibration measurement is also used to determine the impact of blasting on pit walls. However, the effect of blasting vibrations on pit walls is difficult to quantify as vibration is an indirect indicator of cracking, and damage criteria for pit walls are unique to every geological domain.

Displacement and strain measurement have been established as standard geotechnical methods for assessing rock mass behaviour for many years (Little, 2006; Cahill and Lee, 2006). However, established methods generally have a response time that is too slow for the measurements to relate in any meaningful way to the typical blast vibration waveform, where frequencies of up to $10 \mathrm{kHz}$ are sometimes required to fully describe the response of the rock mass.

A method of measuring blast generated transient strain in one dimension was used by Henley (2009). In this work, two time-synchronised vibration monitors were arranged approximately $16 \mathrm{~m}$ apart. The resultant vibration waveforms were integrated to determine the displacement time history and the differential displacement between the two locations calculated at each time step. Yang (2010) extended this and established a method for calculating the strain in three dimensions (3D). Spathis (2010) developed a number of alternative and complementary methods for obtaining a 3D solution. More recently Yang and Ray (2012) describe some data obtained in the first blasting field test using the 3D calculation method based on inverting estimates of displacement gradients to obtain the strain. The calculation method has been integrated into vibration analysis software by Ody and Spathis (2012), and is used here to analyse blast induced strain at the top of a coal mine highwall during 2012. Six blasts were fired during the test period and are reported in this paper.

\section{$2 \quad$ Calculating 2D dynamic strain}

For completeness, and in order to explain one method of calculating the strains from measured vibrations and the derived displacement gradients, a recap of the previous work is given. A fuller and accessible 
exposition is given in Yang and Ray (2012) for 3D strain although we follow the unpublished work of Spathis (2010) and Ody and Spathis (2012) and here focus on a 2D analysis.

The assumptions for the calculation are that we have time-synchronised ground vibrations measured at a number of locations either on the surface and/or below it. In the first instance the rock mass is approximated as an elastic solid and the motion is assumed continuous and linear. The method proceeds by using the dynamic displacements measured at the monitor locations and using the basic equations of linear elasticity (Timoshenko and Goodier, 1970) to form a series of equations that are solved simultaneously for the displacement gradients. The strains are calculated by their definition in terms of these displacement gradients.

Figure 1 shows two points in the rock mass that have been displaced from their original positions $P$ and $Q$ to their new positions $P^{\prime}$ and $Q^{\prime}$. Let $u_{1}, v_{1}$ be the measured displacement components of $P\left(x_{1}, y_{1}\right)$ in the $x$ and $y$ directions respectively, and let $u_{2}, v_{2}$ be those of $Q\left(x_{2}, y_{2}\right)$. Under the assumptions of infinitesimal strain, the changes $\delta u \equiv u_{2}-u_{1}$, and $\delta v \equiv v_{2}-v_{1}$ in the coordinates of point $Q$ relative to point $P$ are given by:

$$
\begin{aligned}
& \delta u=\frac{\partial u}{\partial x} \delta x+\frac{\partial u}{\partial y} \delta y \\
& \delta v=\frac{\partial v}{\partial x} \delta x+\frac{\partial v}{\partial y} \delta y
\end{aligned}
$$

Where we have assumed that the quantities $\delta x \equiv x_{2}-x_{1}$ and $\delta y \equiv y_{2}-y_{1}$ are sufficiently small that higher-order terms can be neglected.
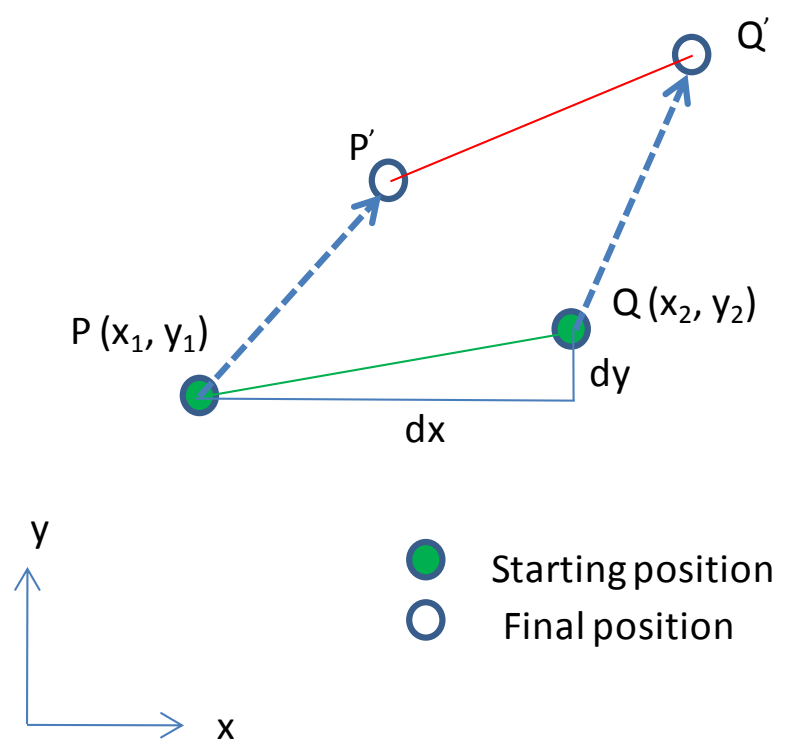

\section{Figure 1 Deformation of a line element $P Q$ into a new position $P^{\prime} Q^{\prime}$}

In Equations (1) and (2) we have four unknown partial derivatives (or displacement gradients) but only two equations. We need another two equations to be able to solve for these four unknown partial derivatives. This is easily done by introducing the deformation of one more point, say $R\left(x_{3}, y_{3}\right)$ which must not be collinear with the other two points. The same analysis applies as above and this will give us another two equations similar to (1) and (2). For the displacement differences of the point $R$ relative to the reference point $P$. If more points are used we have an over-determined set of equations that may be used to obtain the desired displacement gradients using a least squares methodology.

The 2D strains are readily obtained using the following relationships (Timoshenko and Goodier, 1970) where the subscript comma denotes partial differentiation with the variable following it: 


$$
\varepsilon=\left[\begin{array}{cc}
\varepsilon_{x} & \varepsilon_{x y} \\
\varepsilon_{x y} & \varepsilon_{y}
\end{array}\right] \equiv\left[\begin{array}{cc}
u_{, x} & \frac{1}{2}\left(u_{, y}+v, x\right) \\
\frac{1}{2}\left(u_{, y}+v_{, x}\right) & v_{, y}
\end{array}\right]
$$

The diagonal elements of $\varepsilon$ are the normal strains and the off-diagonal elements are the shear strains. There are three independent strains in 2D. The approach above is used at each time step of the time-synchronised vibration recordings. The equations for a 3D analysis are entirely analogous to those above (Yang and Ray, 2012). Of course, the data records may be in terms of particle velocity and it is necessary to transform these to particle displacements; this is done simply by integration and careful filtering as needed by the data quality. The field implementation is important and care is required to ensure that no spatial or temporal aliasing occurs in the recorded data.

The above analysis is quite different to approaches used previously and does not have the limitations or inherent assumptions associated with them. For example, it is well-known that the strain produced by a plane wave is in direct proportion to the particle velocity (White, 1983). However, this is not true for all vibrations and does not apply generally for the specific case of vibrations from blasting.

\section{Field measurements at a central Queensland coal mine}

Orica was asked to measure vibration in a number of locations of the natural surface along the coal mine highwall. The opportunity was used to place an array of four time-synchronised monitors at the monitoring location closest to the blast on the highwall approximately $10 \mathrm{~m}$ from the pit crest. The monitoring array consisted of two GPS time-synchronised monitors, each recording vibration using one tri-axial accelerometer and a tri-axial geophone with transducer axes aligned and horizontal. Sample frequency on all six channels of the monitors was $2 \mathrm{kHz}$. The four sensors were arranged in an approximate square with side length $4 \mathrm{~m}$, and the locations surveyed. A typical arrangement is shown in Figure 2. Sensors were bolted to nylon mounting blocks approximately $150 \mathrm{~mm}$ in diameter and $180 \mathrm{~mm}$ high, and the blocks were buried in the ground with the top of the block level with the ground surface, following the method of mounting vibration transducers in soil recommended by Blair (1995).

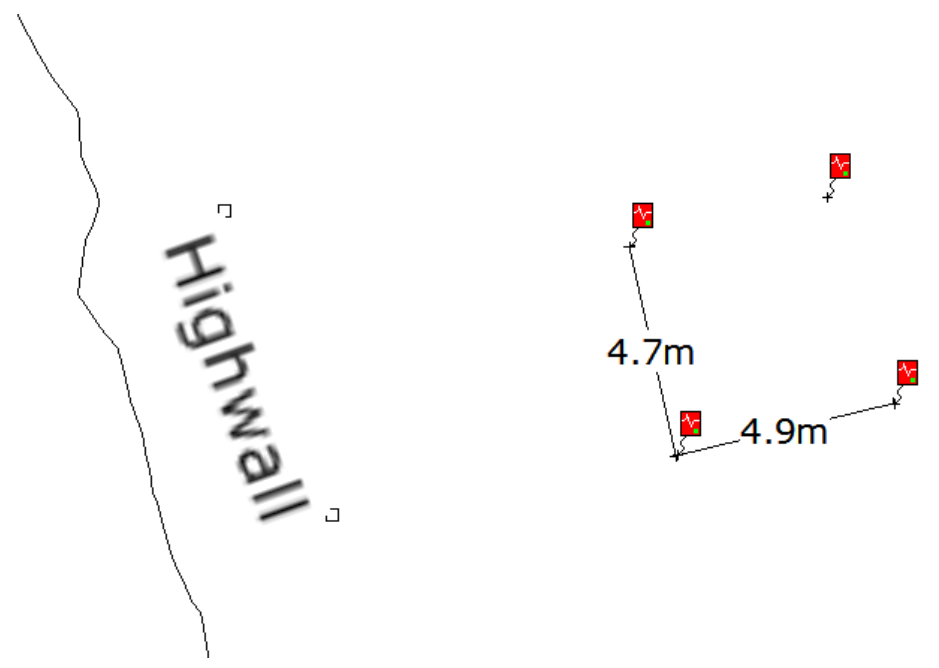

Figure 2 General arrangement of vibration monitor array

The monitors record continuously onto USB memory, using a GPS time signal to ensure time synchronisation with accuracy equal to +/- half the sampling interval $\left(2.5 \times 10^{-4} \mathrm{~s}\right)$. Spacing of the monitors was determined by the need for the monitors to be no more than a quarter of a wavelength apart to avoid aliasing and to ensure strain calculation validity (Naidu, 2009). P-wave velocity in the rock mass had been determined by earlier work to be approximately $3,400 \mathrm{~m} / \mathrm{s}$, so a monitor spacing of $4 \mathrm{~m}$ ensured that the monitors were less than a quarter of a wavelength apart. A monitor spacing of $4 \mathrm{~m}$ ensures valid strain measurement of vibration frequencies up to $200 \mathrm{~Hz}$, and the maximum frequency of the waveforms was no higher than $40 \mathrm{~Hz}$. A frequency spectrum that is typical of most blasts is shown in Figure 3. 


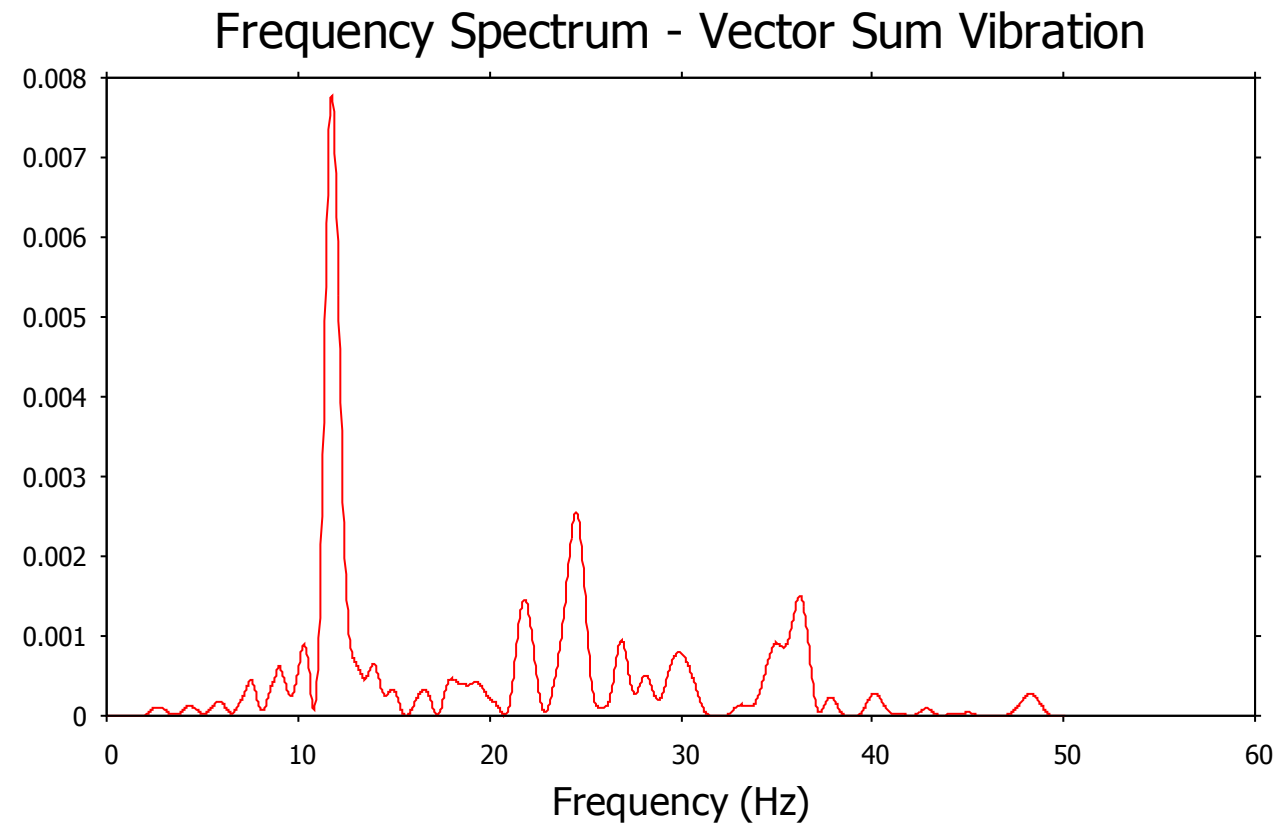

Figure 3 Frequency spectrum of one blast

Blast designs varied with the distance from the highwall. Blasts at greater distance were standard production blasts with minimum control of maximum instantaneous charge weight (MIC), while blasts against the highwall were designed with production and buffer rows against a previously fired presplit. Mine personnel frequently consulted Orica specialists to assist with continuous improving blast designs for minimum vibration at the highwall. An example of a blast against the highwall containing buffer rows is shown in Figure 4. Maximum instantaneous charge weight of explosives (MIC) against time is shown in Figure 5. MIC is calculated for arrivals at the monitor array and is approximately 4,200 kg for this blast.
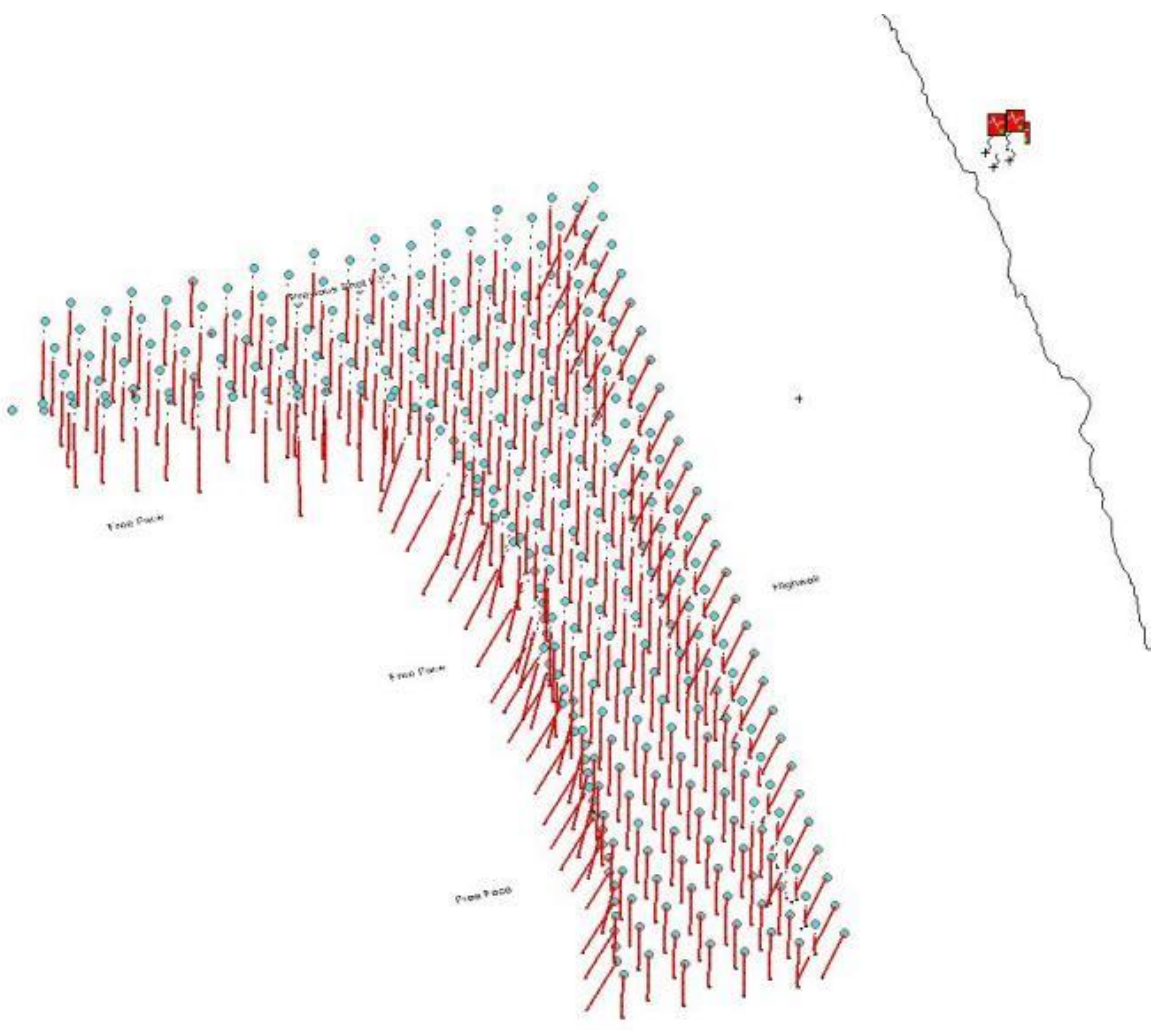

Figure 4 A blast containing trim and production rows of blastholes 


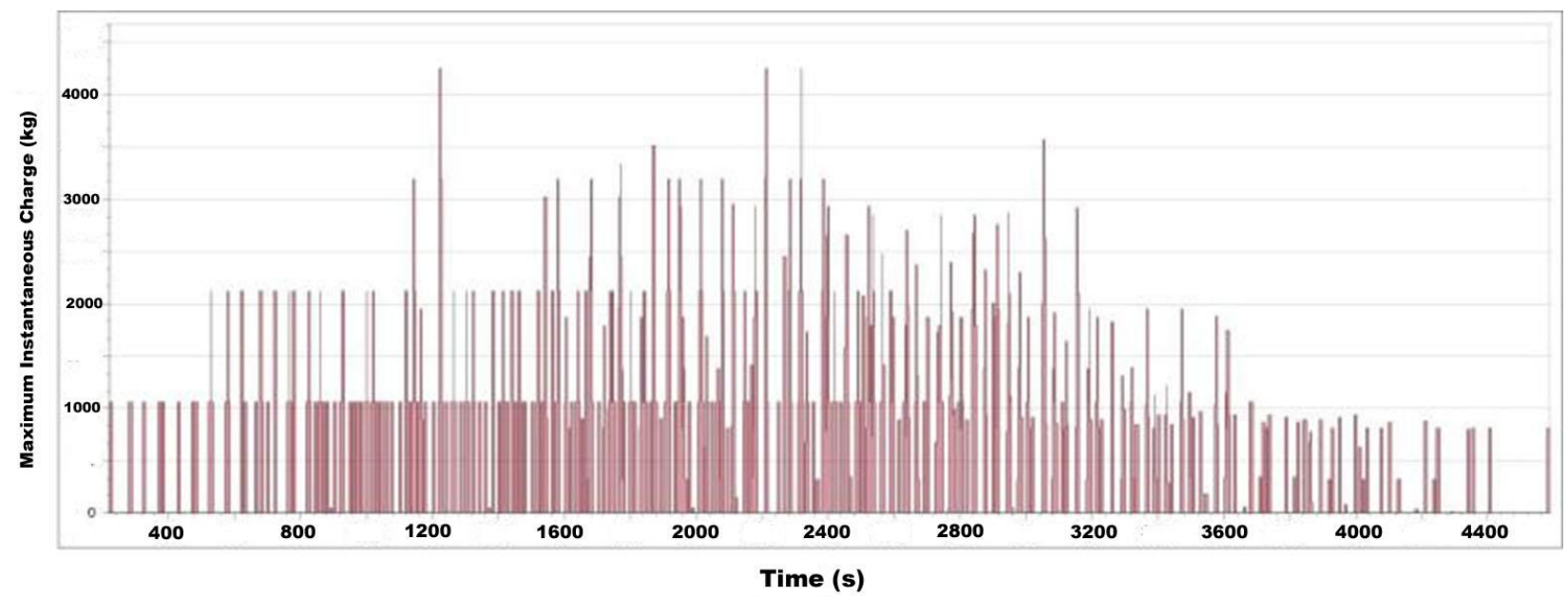

Figure 5 MIC of the blast in Figure 4 calculated at the monitor array

The general blast design configuration used for all production blasts was based on the parameters given in Table 1.

Table 1 Typical blast parameters at the mine

\begin{tabular}{cc}
\hline Blast Design Parameter & Value \\
\hline Hole diameter & $270 \mathrm{~mm}$ \\
Burden & Approximately $8 \mathrm{~m}$ \\
Spacing & From 9 to $16 \mathrm{~m}$ \\
Hole depth & Up to $50 \mathrm{~m}$ \\
Stemming height & 6 to $14 \mathrm{~m}$ \\
Charge weight per hole & Up to $1,400 \mathrm{~kg}$ \\
Initiation timing & Steep V promoting movement \\
& parallel to highwall \\
Burden relief & 16 to $26 \mathrm{~ms} / \mathrm{m}$ \\
Explosive type & HANFO $50 / 50$, HANFO 65/35 \\
\hline
\end{tabular}

Six blasts were monitored using the multiple transducer arrays. No surface cracking was observed in the region of the monitors. An example vibration waveform and the calculated principal strains are shown in Figure 6 . This figure suggests that strain peaks tend to lag vibration peaks by a short time interval. 


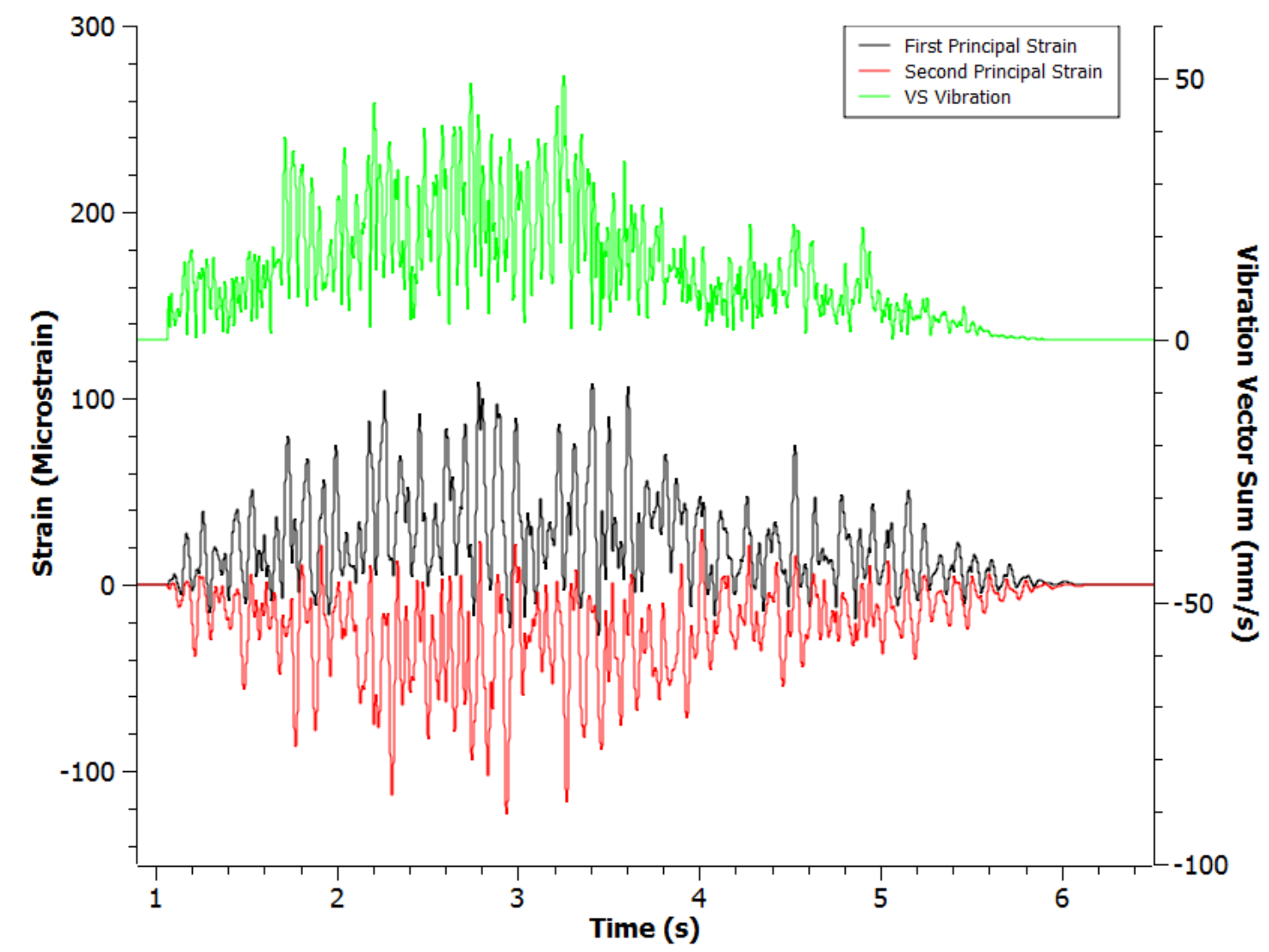

Figure 6 Principal strains and vibration in 2D - Blast \# 5

A summary of the peak vibration and calculated dynamic strain data from all blasts is shown in Table 2 .

Table 2 Peak vibration and principal strain data

\begin{tabular}{|c|c|c|c|c|c|c|c|c|}
\hline \multirow{2}{*}{$\begin{array}{c}\text { Blast } \\
\text { No. }\end{array}$} & \multirow[t]{2}{*}{ Blast Type } & \multirow{2}{*}{$\begin{array}{c}\text { Distance } \\
\text { to Blast } \\
\text { (m) }\end{array}$} & \multirow{2}{*}{$\begin{array}{l}\text { MIC } \\
\text { (kg) }\end{array}$} & \multirow{2}{*}{$\begin{array}{c}\text { Max } \\
\text { ppv } \\
(\mathrm{mm} / \mathrm{s})\end{array}$} & \multicolumn{4}{|c|}{ Peak Strains (Microstrain) } \\
\hline & & & & & $\begin{array}{c}\text { 1st } \\
\text { Principal } \\
\text { Strain }\end{array}$ & $\begin{array}{c}\text { 2nd } \\
\text { Principal } \\
\text { Strain }\end{array}$ & $\begin{array}{l}\text { Shear } \\
\text { Strain }\end{array}$ & $\begin{array}{c}\text { Octahedral } \\
\text { Shear } \\
\text { Strain }\end{array}$ \\
\hline 1 & Production & 280 & 3,880 & 60.6 & 265 & -270 & 65.1 & 107 \\
\hline 2 & Production & 230 & 4,000 & 65.1 & 191 & -197 & 136 & 228 \\
\hline 3 & Production/buffer & 115 & 4,600 & 170 & 353 & -311 & 300 & 594 \\
\hline 4 & Production/buffer & 124 & 2,800 & 226 & 592 & -656 & 275 & 455 \\
\hline 5 & Production/buffer & 175 & 4,250 & 75.6 & 108 & -123 & 75.6 & 127 \\
\hline 6 & Production/buffer & 81 & 3,800 & 75 & 179 & -194 & 116 & 202 \\
\hline
\end{tabular}

\section{$4 \quad$ Application}

The measurement of the dynamic strains described offers the potential to help pit designers understand the impact of blasting on slopes and highwalls. The technique is in its infancy and as an initial approach the application of simple strain failure criteria could be applied to measurements conducted in brittle rocks. With rock elastic limits established through testing, the range of methods listed in Kwasniewski and Takahashi (2010) provide a basis on which to assess failure of brittle rock using this technique:

- Critical Extension Strain (Stacey, 1981). 
- Critical Strain (Sakurai, 1981).

- Maximum Shear Strain (Sakurai et al., 1995).

- Critical Tension Strain (Fujii et al., 1993).

- Octahedral Shear/Max. Principal Strain (Kwasniewski and Takahashi, 2010).

In the first four of the above criteria, the peak dynamic value can be compared against rock testing results to determine whether the critical or failure strain is being approached by the blast induced strains. For the last criterion above, establishing the relationship between octahedral shear strain versus maximum principal strain at failure through rock testing will provide a failure envelope that can be plotted with the time history and can show whether the failure envelope is approached. Data from blast 5 using this criterion is shown in Figure 7. Tri-axial testing results (that were unavailable) are required to plot a failure criterion on the dynamic data in Figure 7.

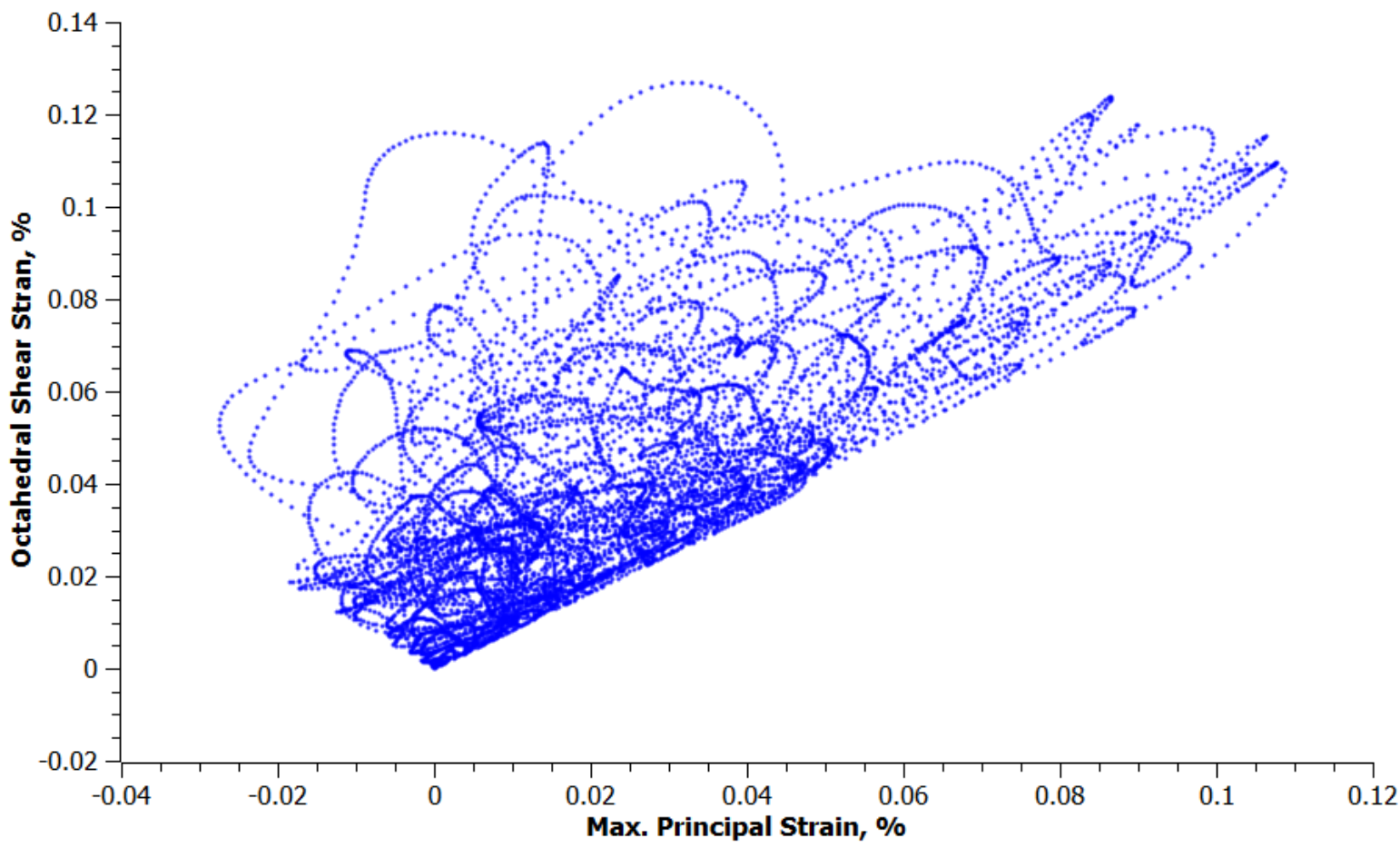

Figure 7 Dynamic plot of octahedral shear strain versus maximum principal strain using a $0.5 \mathrm{~ms}$ plot interval

\section{Conclusions}

A preliminary assessment of a novel method for estimating dynamic strains from vibration data for several blasts near a coal mine highwall was described. The technique is in its infancy and the failure mechanism of the highly weathered sediments measured in this work cannot be confirmed without material testing results. It is expected that the approach will enhance geotechnical evaluation of slope and pit walls impacted by blast vibrations. Effects such as repeated blast loading and close proximity blasting may be assessed over time and integrated with other monitoring techniques applied at mines.

\section{Acknowledgement}

Orica Technical Service Engineers: Ross Taylor, Geoff Adderley and Melissa Smith, who took the extra time to collect the field data for this study. We also thank our colleagues Ruilin Yang, Scott Scovira and Mike Ody for many discussions on using blast vibration data to estimate dynamic strains. 


\section{References}

Blair, D.P. (1995) Soil-embedded detector mounts for seismic monitoring, Geophysics, Vol. 60 (1), pp. 120-133.

Cahill, J. and Lee, M. (2006) Ground control at Leinster Nickel Operations, in Proceedings International Symposium on Stability of Rock Slopes in Open Pit Mining and Civil Engineering, 3-6 April 2006, Cape Town, South Africa, The Southern African Institute of Mining and Metallurgy.

Fujii, Y., Kiyama, T. and Ishijima, Y. (1993) New failure criterion for rock, Shigen-to-Sozai, The Mining and Materials Processing Institute of Japan, ISSN:0916-1740, Vol. 109, No. 7, pp. 549-550 (in Japanese).

Henley, K. (2009) Vibration Site Law Analysis, Orica Internal report.

Kwasniewski, M. and Takahashi, M. (2010) Strain-based failure criteria for rocks: State of the art review and recent advances, in Proceedings EUROCK Rock Mechanics in Civil and Environmental Engineering, Z. Zhao, V. Labouise, J.P. Dudt and J.F. Mathier (eds), 15-18 June 2010, Lausanne, Switzerland.

Little, M.J. (2006) Slope monitoring strategy at Prust Open Pit Operation, in Proceedings International Symposium on Stability of Rock Slopes in Open Pit Mining and Civil Engineering, 3-6 April 2006, Cape Town, South Africa, The Southern African Institute of Mining and Metallurgy.

Naidu, P.S. (2009) Sensor Array Signal Processing (2nd Edition), CRC Press, Boca Raton, Florida, USA.

Ody, M.S. and Spathis, A.T. (2012) Software Implementation of the Calculation of Dynamic Strains and Rotations from Displacement Measurements, Orica Technical Report: Category B.

Sakurai, S. (1981) Direct strain evaluation technique in construction of underground openings, in Proceedings 22nd U.S. Symposium on Rock Mechanics, 29 June-2 July 1981, Cambridge, MA, pp. 278-282.

Sakurai, S., Kawashima, I. and Otani, T. (1995) A criterion for assessing the stability of tunnels, in Proceedings Safety and Environmental Issues in Rock Engineering, L. Ribeiro, E. Sousa and N.F. Grossmann (eds), ISRM International Symposium EUROCK '93, 21-24 June 1993, Lisbon, Portugal, Vol. 2, Balkema, Rotterdam, pp. 969-973.

Spathis, A.T. (2010) The calculation of the dynamic strain tensor from particle displacement measurements, Orica Technical Report: Category B.

Stacey, T.R. (1981) A simple extension strain criterion for fracture of brittle rock, International Journal of Rock Mechanics and Mining Sciences, Abstract, Vol. 18, pp. 469-474.

Timoshenko, S.P. and Goodier, J.N. (1970) Theory of Elasticity, 3rd edition, McGraw-Hill, New York.

White, J.E. (1983) Underground Sound, Elsevier, Amsterdam, The Netherlands.

Yang, R. (2010) Method to calculate 3-D dynamic strain tensor from blast vibration monitoring, Orica Internal Technical Report.

Yang, R. and Ray, K. (2012) A Method to Determine the 3-D Dynamic Strain Tensor Based on Displacement Gradients from Blast Vibration and Field Test Results, Fragblast, Vol. 10, 24-29 November, New Delhi, India. 